\title{
Von Kardialem und Kardinalem
}

\section{Daniel Lüthi}

Text und Bilder
Er hat Verschiedenes geschrieben und publiziert in seinem Leben, Wissenschaftliches aus seinem medizinischen Spezialgebiet zuerst einmal: «Perimyokarditis oder spasmusbedingte Myokardnekrose?» heisst eine seiner Veröffentlichungen. Sein wohl wichtigstes medizinisches Buch aber trägt den Titel: «Das EKG Auf einen Blick und im Detail»[1]. Es widerspiegelt den Arzt Marc Gertsch. Und der wäre seinerzeit beinahe Pianist geworden. Diese Seite scheint in einem Buch über musikalische (und andere) Begegnungen [2] auf und in einer privaten CD, die Sohn Gustav - er hat das Pianospiel zum Beruf gemacht - mit frühen Aufnahmen des Vaters zusammengestellt hat.

Nach seiner Pensionierung wurde aus dem Kardiologen der Krimi-Autor. Warum? «Eine kleine schöpferische Tätigkeit», sagt er selber, so gut es eben noch geht. Sprechen fällt ihm schwer. Denn inzwischen ist für Marc Gertsch das Leben selbst zum Krimi geworden, zur spannenden Frage: «Und was passiert als nächstes?»

Literarisch wurde Marc Gertsch erst nach der Pensionierung 2001 aktiv. Ein glücklicher Zufall spielte ihm für seine neue Tätigkeit im alten Umfeld einen neuen Arbeitsort zu: Ein befreundeter Arzt am Berner Inselspital erhielt ein neues Büro. Das ehemalige Zimmer im Estrich der alten Augenklinik wurde zur Schreibstube - und zur Geburtsstätte des hinkenden Kardinals. Warum machte Marc Gertsch ausgerechnet die katholische Kirche zum Hintergrund seines Krimis?

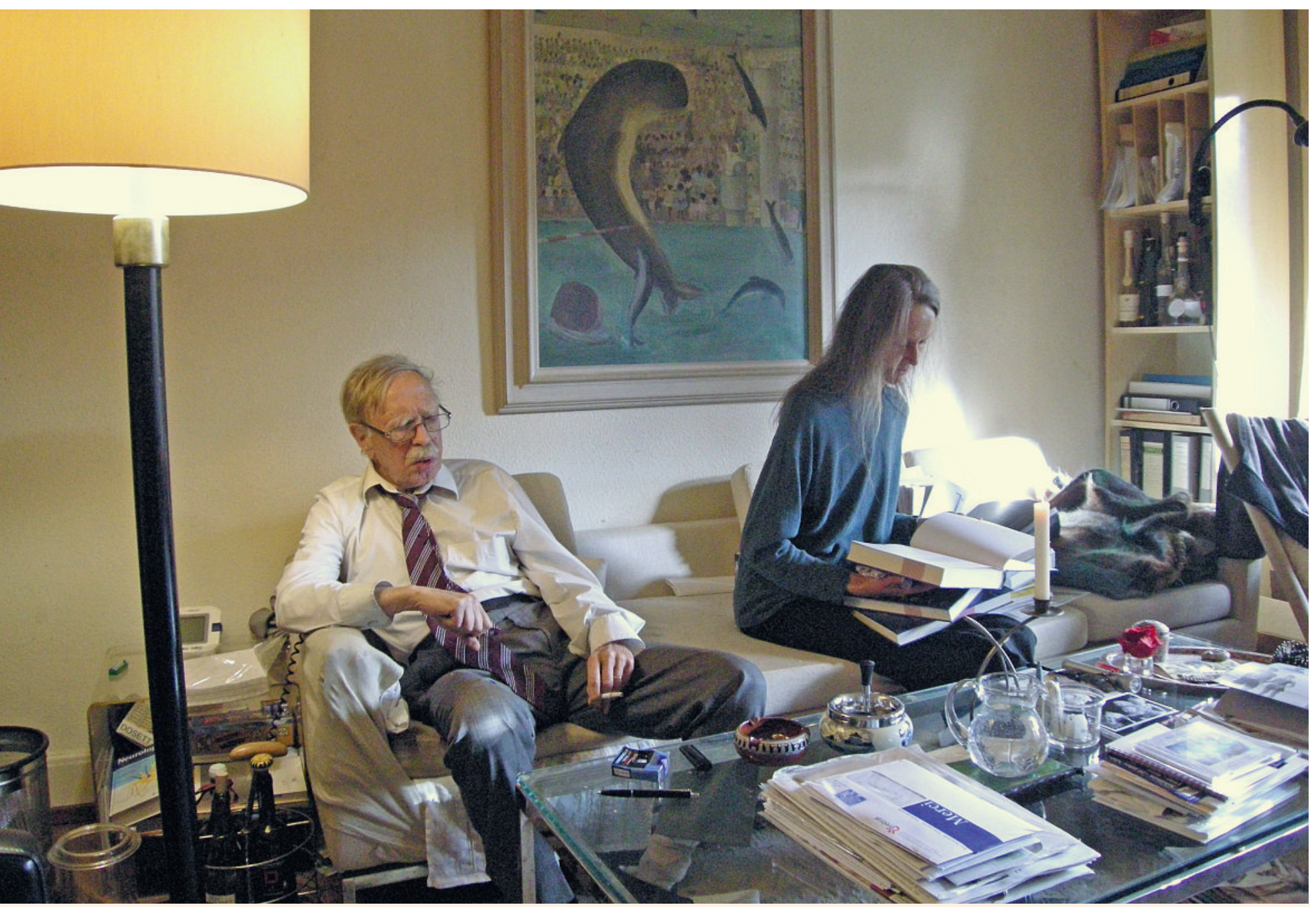

Eindrücklicher Zusammenhalt: Marc Gertsch und seine Frau Ursula sind praktisch seit ihrer Kindheit ein Paar. 

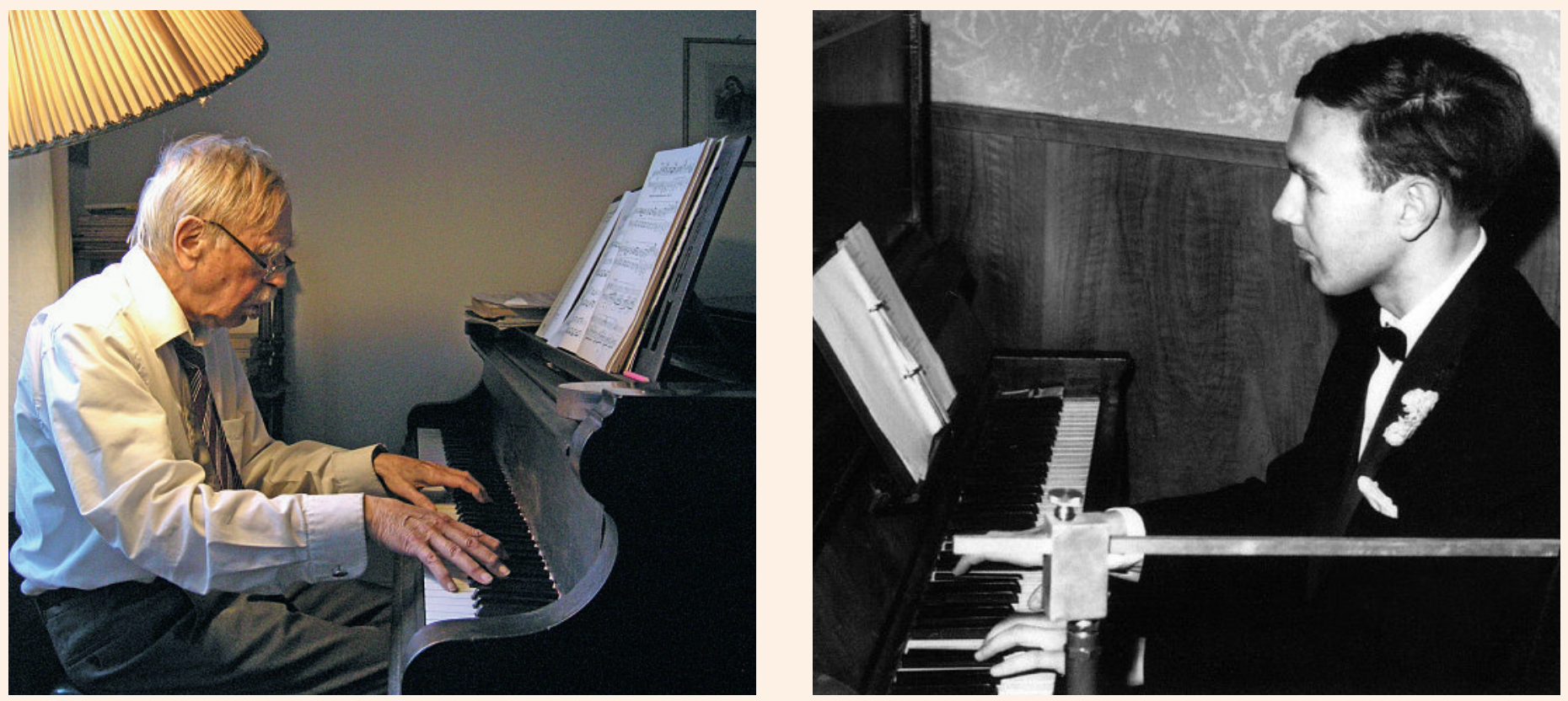

Arzt, Krimiautor und begnadeter Pianist: Noch heute spielt Marc Gertsch (rechts in jungen Jahren) täglich mindestens eine Stunde lang Klavier.

Die Antwort ist ebenso kurz wie schelmisch: «Warum nicht?».

Klarer ist der Bezug zum geografischen Umfeld: Seit 25 Jahren besitzt die Familie Gertsch in der Nähe von Siena ein Haus, deshalb kommt die Hauptperson des Krimis, Polizeipräsident Marconi, auch von dort. runter, nicht mehr ganz rein, aber herzhaft, dann eine Sequenz aus dem Klavierkonzert von Grieg. «Er probiert einfach», sagt seine Frau Ursula, «ist doch gut, oder?»

Ursula und Marc sind praktisch seit ihrer Kindheit ein Paar. Es ist eindrücklich, zu erleben, wie die

Für Marc Gertsch selber ist der Link zwischen ihm als Medizinprofessor und Krimiautor sehr direkt: «Als Arzt eine Diagnose zu stellen, hat auch etwas Kriminalistisches», sagt er.

Überhaupt: Die Toskana ist stark präsent in diesem Buch, bis hin zu kulinarischen Details - die Faszination des Autors für Italien und seine Küche ist augenfällig. Aber auch Wien kommt vor, dort hat Marc Gertsch 1958 ein Auslandsemester verbracht, und dort wäre er beinahe auch professioneller Pianist geworden.

Noch heute spielt Marc Gertsch täglich mindestens eine Stunde lang Klavier. Auch jetzt, bei unserem Treffen, steht er plötzlich auf und geht, so gut es noch geht, ins Zimmer nebenan, setzt sich ans Piano, legt los. Die Noten, die dort stehen, kann er nicht mehr lesen, weil er kaum mehr etwas sieht. Aber die Finger sind noch beweglich und die Erinnerung macht die schwindende Sehkraft wett. Tonleitern jetzt, rauf und beiden noch heute zusammenhalten. Gerade jetzt, wo für beide das Leben immer komplizierter und schwieriger wird.

«Polyneuropathie» ist eine der Diagnosen. Zum Glück war der Krimi vorher fertiggeschrieben. Denn die positiven Reaktionen darauf geben jetzt Kraft. «Den Leuten gefällt die Spontaneität», sagt Marc Gertsch. Und dass er gar keine Literatur habe produzieren wollen, «nur eine Geschichte erzählen». Es ist eine spannende, süffige Geschichte. Mafiosi kommen darin vor, ein Papst, der stirbt, uneheliche Kinder und langbeinige Stewardessen - und natürlich die beiden Brüder, bei denen ein Mord möglich ist. Eine Blinddarmreizung auf Seite 9 ist der erste Hinweis auf den medizinischen Hintergrund des Autors, eine Rücken- 
markverletzung und Gewebeproben zur Feststellung der Identität sind weitere Indizien. Für Marc Gertsch selber ist der Link zwischen ihm als Medizinprofessor und Krimiautor sehr direkt: "Als Arzt eine Diagnose zu stellen, hat auch etwas Kriminalistisches», sagt er, «da arbeitet man ähnlich wie ein Detektiv.»

«Hinkte der Kardinal richtig oder falsch?»: Das ist die Kardinalfrage im Buch. Die Kardinalfrage des Kardiologen ist heute eine andere. Wie auch immer: Die Freude an der Arbeit und der Ehrgeiz sind Marc Gertsch geblieben. Ein Theaterstück sei unterwegs, sagt er, ein fiktives Gespräch zwischen Mozart und Goethe. Unglaublich. Unglaublich übrigens, wie viel der Mann - seit vielen, vielen Jahren - raucht: Gauloises blau ohne Filter, eine nach der anderen. «Ausgerechnet er als Herzspezialist», sagt seine Frau, eher amüsiert als vorwurfsvoll. Sie ist zunehmend nicht nur seine Betreuerin, sondern auch seine Übersetzerin. Auch dies eine Tatsache, die beide nicht zu verheimlichen suchen. Mit berührender Offenheit nehmen sie die Realität, wie sie sich präsentiert. Welch ein Gegensatz zum fantastischen Fabulieren im Buch, zu den springenden Delfinen auf dem Bild über dem Sofa - und zur Realität von früher!

Eines jedoch verbindet alles: das Herz.

\section{Literatur}

1 Englische Original-Ausgabe: Gertsch M. The ECG A Two-Step Approach to Diagnosis. Berlin: Springer; 2004.

Deutsche Übersetzung: Gertsch M. Das EKG: Auf einen Blick und im Detail. Heidelberg; Springer; 2007, 2008

2 Gertsch M. Persönlich. Bern: Müller \& Schade; 2010.

«Der Kardinal hinkt»
Als der Polizeipräsident von Siena, Questore
Angelo Marconi, im Fernsehen zufällig einen
Bericht über eine Prozession in Mailand mitver-
folgt, stutzt er. Die Prozession wird von Kardinal
De Santo angeführt, und obwohl er den Kardinal,
seinen ehemaligen Lehrer an der Klosterschule,
seit Jahren nicht mehr gesehen hat, fällt dem
Questore sofort auf, dass mit ihm etwas nicht
stimmt. Aber was ist es, was ihn stutzen lässt?
Erste Nachforschungen verdichten diese Zweifel -
und als sich plötzlich die Mafia für Marconi inter-
essiert, weiss dieser nicht mehr, wem er über-
haupt noch trauen darf. Sicher ist nur eines: Jetzt
steht sein Leben auf dem Spiel.

